\title{
Does Learning Process Mediate the Relationship between Social Control and Production Innovation of International Joint Ventures in China?
}

\author{
Cheng Wang, Hailin Lan, Hongming Xie \\ School of Business Administration, South China University of Technology, Guangzhou, China. \\ Email: fly2018@yahoo.com.cn
}

Received October $23^{\text {rd }}, 2009$; revised December $2^{\text {nd }}, 2009$; accepted January $16^{\text {th }}, 2010$.

\begin{abstract}
A comprehensive model that delineates the interrelationships among social control, learning process and production innovation in international joint ventures is absent. This study aims to fill this void. Unlike previous research, this study investigates the role of social control, in facilitating learning process and production innovation in China. In our framework, we argued that learning process mediated the impact of social control on production innovation. In order to test the feasibility of this framework, we conducted an empirical study. This study employed a survey instrument, which contained data collected from 300 organizations international joint ventures in South China. A total of 96 usable responses were analyzed. The results indicate that social control has a positive impact on learning processes and production innovation. Learning process partial mediate the influence of social control on production innovation. The implications of the study are provided, and future research is suggested.
\end{abstract}

Keywords: Learning Process, Production Innovation, Social Control, International Joint Ventures

\section{Introduction}

International joint ventures (IJV) are now a common organizational form. Increased international joint venture activity has been seen as one of the major changes in international business environment in the past decade. The exercise of managerial control has been one of the most important subjects in the IJV literature. Control has long been recognized as an important aspect of an organization's management of exchange relationships. Although control considerations are important for any organization, they are especially so when managing organizational exchanges across diverse national environments. The major function of control involves bringing about conformance to organizational requirements and achievement of ultimate purpose of the organization.

While the literature reflects a fair amount of effort directed toward an understanding of control exercised as well as its antecedents and consequences [1-3]. It provides very little, if any, guidance about the effectiveness of various control mechanisms across different innovation modes used in structuring international principal agent exchange relationships.

Although firms form IJVs for a variety of reasons, interorganizational learning has become an important ra- tionale for their creation $[4,5]$. While an IJV's parents often seek to learn from one another, IJV learning from its foreign parents is considered to be essential for its survival, hence, the realization of the parents' strategic goals $[6,7]$.

Consider first technology-related capabilities. A highly technologically turbulent environment is characterized by a short cycle of technological innovation and obsolescence. In high turbulence, technology-related capabilities (such as innovation) should enable an IJV to shape or react to these environmental conditions [8]. For example, the timely introduction of new products to replace obsolete products may become crucial to firm success [9].

The purposes of this study are: a) to examine the role of social control in facilitating learning process; b) to realize the impact of learning process on the effect of adopting social control to facilitate production innovation.

This article proceeds as follows. First, the theory of social control is examined, focusing on the role of distinctive capabilities in innovation-based competitive strategy. Second, the conceptual framework describing the focal constructs and theoretical relationships intended to be tested is discussed. Third, the method used to test the hypotheses is discussed. Next, the results, based on analysis of data collected from 96 firms of international 
joint ventures in China, are presented. The paper concludes by discussing implications for innovation theory and practice, identifying limitations of the study and providing directions for future research.

\section{Theoretical Backgrounds and Hypothesis}

\subsection{Social Control}

For many decades the topic of control has been a source of considerable discussion and thus it is not surprising to find a variety of approaches to conceptualizing and operational sing control.

Social control represents an informal control mechanism based on prevailing social perspectives and patterns of interpersonal interactions within a firm. In socially controlled exchange relationships, behavior is specified by the organizational culture, and performance is viewed as a social obligation maintained via mechanisms of social pressure [10]. Social control relies on implicit organization wide culture to monitor agents' behavior and to orient them toward organizational rather than parochial goals.

Similarly, socially controlled relationships are characterized by shared values and a common sense of wellbeing among members. Reliance on social control in external relationships assures that each partner is being treated fairly which in turn facilitates community interests fostering greater relationship flexibility. However, in internal exchanges, social controls are expected to be especially instrumental in making agents feel an integral part of the team, fostering shared values and aligning interest thereby leading to much greater relationship flexibility and adaptability. As a result, principals and agents can adopt a longer term perspective by balancing immediate results with long term nurturing relationships with each other. This is necessary because existence and continuity of social control requires stability of the exchange partners which in turn necessitate compromise and adaptability.

Through the process of socialization and indoctrination, the agents can be accounted wide latitude enabling them to respond to conditions quickly and in a manner consistent with long-term organizational goals and objectives. The socialization process can be used to create shared values and common interest among independent parties to encourage flexible and negotiated adjustment as well as to improve economic performance in terms of both sales growth and market share increases. Furthermore, by using social controls that sanction rather than punish risk taking, agents can be encouraged to try innovative approaches to achieve organizational performance objectives [11].

\subsection{Learning Process}

Acquiring knowledge related to those capabilities from foreign parents critical to the transitional economy IJVs' survival. As noted earlier, the survival of the IJV is a prerequisite for the domestic and foreign parents to achieve their goals. It is also a prerequisite for the domestic government to achieve its goals $[12,13]$. The common interest of all stakeholders in the survival of a transitional economy IJV creates strong incentives for the IJV and its parents to focus on its learning from the foreign parent. Hence, the analysis of organizational learning has become an increasingly important study area in international joint ventures. Organization learning involves the basic elements and processes of organizational development and growth. From a learning perspective, organizations grow when there is an increase in shared understanding involving the organization, its environment and the relationship between the two. A parent adopting a learning-oriented cooperative strategy usually possesses clear learning intent, which, in this study, refers to the level of desire and will of the parent with respect to learning from the international joint venturing experience.

Discussions of individual learning generally refer to the product of the learning process as changes in beliefs (or cognition) and changes in behavior. The term skill is often used to describe behaviors for which an individual has developed a level of expertise or proficiency. In a reliable learning process, an organization develops common understandings of its experience and makes its interpretations public, stable and shared. In a valid learning process, an organization understands, predicts and controls its environment. As organizations engage in learning efforts, neither reliability nor validity is assured because different people and groups in an organization approach historical experience with different expectations and beliefs. As we found, shared understanding about the value of IJV learning experiences was often obstructed by the variety and differences in managerial beliefs.

\subsection{Production Innovation}

Resource-based theory views a firm as a unique bundle of tangible and intangible resources and emphasizes the protection of firm core competencies comprising these resources. Staying on top of innovation and creativity in business is necessary for a business to stay ahead of the competition. New product introduction indicates the potential significance of a firm's innovation activities. New products are a central mechanism by which organizations diversify, adapt, and reinvent themselves in changing market and technical conditions [14].

In the past 20 years, many potentially useful typologies have been proposed, each providing insight to our understanding of the innovation process. Three of the most popular typologies are based on the distinctions between administrative and technical innovations, prod- 
uct and process innovations, and radical and incremental innovations $[15,16]$. Technical innovations include products, processes and technologies used to produce products or render services related to the basic work activity of an organization. Product and process innovations are distinguished based on the different areas and activities that each of them affect within the firm [17]. Product innovations are outputs or services that are introduced for the benefit of customers or clients.

Accordingly, the following hypothesis is advanced:

H1: The higher the level of social control, the higher the level of learning process

$\mathrm{H} 2$ : social control is a function of its production innovation

H3: learning process will significantly impact on production innovation

In order to explore the impact of social control and learning process on production innovation, we developed the research framework in Figure 1. There are two research questions. a) Does social control play a role in facilitating learning process? b) Does learning process mediate the effect of social control on facilitating production innovation?

\section{Methods}

\subsection{Sample}

Data were collected from international joint ventures of China through a survey instrument. An initial version of the survey instrument was developed based on the theory-grounded operationalization of the various constructs. This version was subsequently revised through pretesting with academic and experts. The multiple phases of instrument testing and development resulted in a significant degree of refinement and restructuring of the survey instrument as well as establishing the initial content validity [17]. We had three sampling criteria: the firms had to be 1) at least 1years; 2) at least 50 employees; 3) manufacturing and service firms in South China. We received responses from 118 of $300 \mathrm{IJV}$ firms, a response rate of 39.3 percent. Of the 118 returned questionnaires, 16 were excluded because they did not meet all sampling criteria and 6 were excluded because of incomplete ans-

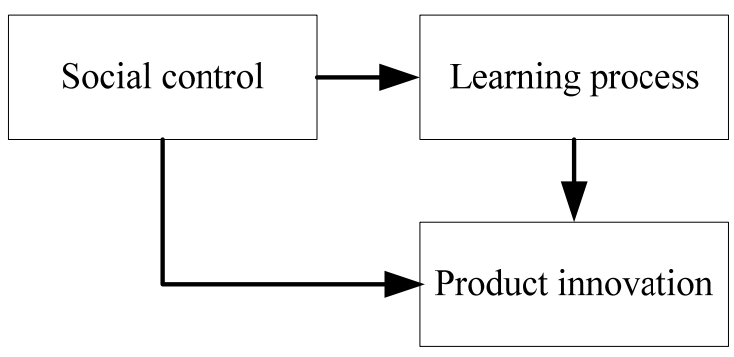

Figure 1. Research framework wers, leaving 96 usable responses. Hence, our usable response rate was approximately 32 percent.

Location and age data on no respondents indicate no significant differences between respondents and no respondents. Because those responding late are argued to be similar in composition to no respondents, we also tested for response bias by comparing early against late respondents. We found no significant differences in terms of sales, employees, or international sales. The results of statistical tests for response bias suggest that our sample is representative of the firm satisfying our criteria.

\subsection{Reliability and Validity}

Factor analysis using principal components factor analysis with factor extraction and VARIMAX rotation was conducted to examine the convergent and discriminant validity [18]. The four commonly employed decision rules were applied to identify the factors [19]: 1) minimum Eigen value of 1 ;2) minimum factor loading of 0.4 for each indicator item; 3 ) simplicity of factor structure; and 4) exclusion of single item factors. Reliability was evaluated by assessing the internal consistency of the indicator items of each construct by using Cronbach's $\alpha$ [20].

The results of factor analysis relating to convergent validity are shown in Appendix.

\subsection{Measures}

Social control represents an informal control mechanism where monitoring occurs through interpersonal interactions. As Jaeger and Baliga (1985) [21] notes, in socially controlled exchanges, one would expect the interactions between the principal and foreign agents to be weighted in favor of personal contacts such as visits, social meetings, and use of expatriates. Based on this conceptualization, a five-item scale was developed to capture the informal interactions and socialization opportunities in principal-agent relationships. Alpha coefficient for this five item scale is 0.80 .

Following Chou (2003) [22], learning process consist of decision to contribute and decision to adopt. For an individual to contribute knowledge one has to formulate the tacit and explicit knowledge about what has been learned, what the problems were, what kind of knowhow I used to solve the problems, and what the context for a solution was. The other activity for 'contribute' is to delivery such knowledge to the person who needs it. In order to do so, knowledge has to be represented in a way that is meaningful and easy to understand to others. In order to adopt knowledge, an individual has to search for the possible solutions and match the problems to the appropriate solutions. Alpha coefficient for this seven-item scale is 0.85 . 
Product innovation was adapted from the scale developed by XIE Hongming and Wang Cheng et al. (2007) [23]. Product innovation is measured by a five-item scale. Production innovation Alpha coefficient for this fiveitem scale is 0.85 .

\section{Analysis and Results}

The means, standard deviations and correlations of all the variables are reported in Table 1. The bivariate correlations show that similarity is significantly related to social control, learning process and production innovation. Although the bivariate relationships support our hypothesis, we use structural equation modeling approach to actually test the hypothesis, thereby taking into account any relationships between the latent variables and observable indicators.

A structural equation modeling approach was applied to the data using the AMOS version 7.0 software packing. Figure 2 and Table 2 shows the results of the competing model analysis. Although the $\chi^{2}$ statistic for each model is significant, other relevant fit indices indicate good overall fit. The results show that learning process partial mediates the relationship between social control and production innovation. First, positive relationships exist between social control and learning process $(\mathrm{H} 1: \beta=0.27$, $t=2.099)$ and learning process and production innovation (H3: $\beta=0.36, t=2.913$ ). Second, the significant relation ship between social control and production innovation
Table 1. Means, standard deviations, correlations

\begin{tabular}{lccccc}
\hline \multicolumn{1}{c}{ Multi-item scales } & Means & S.D. & 1 & 2 & 3 \\
\hline (1) Social control & 3.316 & 0.663 & 1.000 & & \\
(2)Learning process & 3.826 & 0.498 & $0.276^{* * *}$ & 1.000 & \\
(3) Production innovation & 3.330 & 0.695 & $0.447^{* * *}$ & $0.412^{* * *}$ & 1.000 \\
\hline
\end{tabular}

indicated in the direct effects model $(\beta=0.53, t=3.681)$, it is also significant in the partial mediation model $(\mathrm{H} 2$ : $\beta=0.44, t=3.286$ ). Together these three points provide compelling evidence that there exists a partial mediating effect of learning process on the relationship between social control and production innovation.

\section{Conclusions and Discussions}

This study investigated the role of social control in facilitating learning process and production innovation. Based on 96 respondents from organizations in manufacturing, the service industry of international joint ven tures in China, we found that the functions of social control have a positive impact on the organizational learning processes. We also examined the impact of learning process on the adopting of social control to facilitate production innovation. Two interesting results were found. First, learning process is related to the effect of adopting social control to facilitate production innovation. Second, learning process partial mediates the influ-

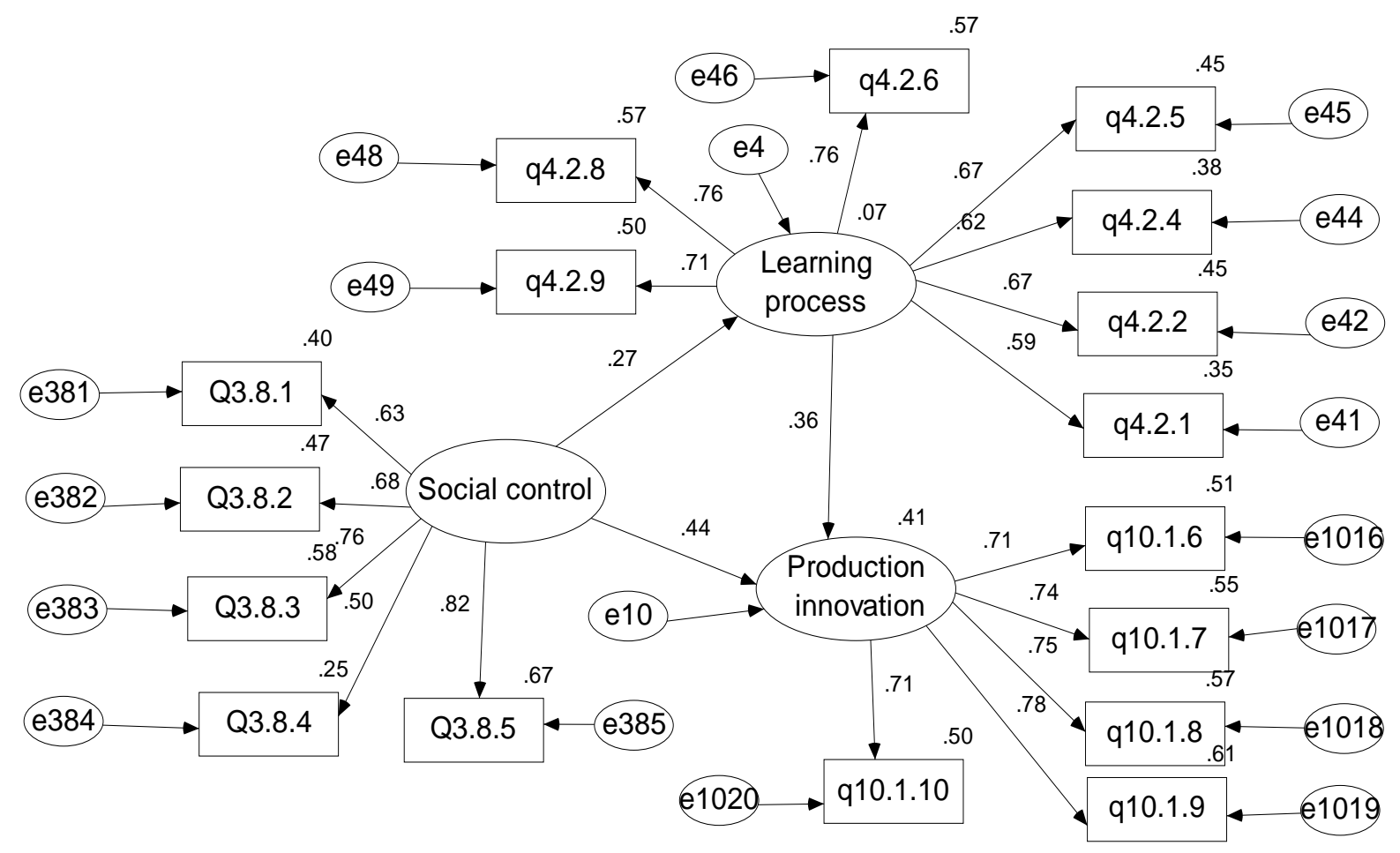

Figure 2. The overall theory model and parameter 
Table 2. Test results that learning process partial mediate the influence of social control on production innovation

\begin{tabular}{ccc}
\hline Parameter & Direct effects model & Partial mediation model \\
\hline Hypothesized paths & - & $0.27(2.099)$ \\
Social control $\rightarrow$ Learning process & $0.53(3.681)$ & $0.44 .(3.286)$ \\
Social control $\rightarrow$ Product innovation & - & $0.36(2.913)$ \\
Learning process $\rightarrow$ Product innovation & $=53.624$ & $=204.397$ \\
Goodness-of-fit statistics & $=34$ & $=0.809$ \\
$\chi^{2}$ & $=0.903$ & $=0.871$ \\
d.f. & $=0.947$ & $=0.849$ \\
GFI & $=0.930$ & $=0.051$ \\
Comparative fit index(CFI) & $=0.044$ \\
Tucker-Lewis index(TLI) & $=0.078$ & $=0.090$ \\
RMR & &
\end{tabular}

ence of social control on production innovation. Unlike previous research, this paper examines the impact of social control on production innovation in a more comprehensive way. First, we integrate social control, learning process and production innovation in a theoretical model. Second, we conducted an empirical study to specify the learning process that mediates the influences of the adoption of social control on facilitating production innovation. By emphasizing the features of social control, we may facilitate the effect of learning process. On the other hand, we cannot overlook learning process, since it may increase or decrease the effect of production innovation. The implications of this study are three fold.

First, this research explores the social control features that may facilitate learning process. Some of the features are new in supporting learning process. Understanding the features of learning process that facilitate organizational learning is very helpful for management. Managers should emphasize the learning process.

Second, understanding the characteristics of the organizational learning process in an in international joint ventures environment may help us to design the facilitating mechanisms accordingly. The difference of the organizational learning process between in international joint ventures and regular environment is therefore worthy of future research.

Finally, our empirical study identified social control and learning process synergistic affect production innovation. In order to obtain the most effective way of production innovation, it is crucial that managers develop social control adopting strategy. This study further supports the belief that production innovation should be congruent with the learning process international joint ventures. To promote production innovation, firms should actively manage their learning processes. Whenever a new IJV is set up, its learning potential has to be carefully evaluated. Management should examine wheth- er the IJV provides novel and useful management experience and whether knowledge can be acquired from other partners of the IJV. The evaluation step has to be followed by allocating appropriate resources for the purpose of learning. To exploit the learning potential identified above, clear objectives with respect to learning have to be set for managers who are sent to work in the IJV.

Like all research, this study has left some unanswered questions that suggest avenues for future research. First, our sample of South China may not be representative of China. Thus, a direction for future research would be to test the various hypotheses in this study using a broader sample of China. Further, the sample size, 96 IJV, was relatively small, which might account for some of the marginal effects that we observed; future research should aim to replicate this study with a larger sample. Second, the use of data and analysis do not allow the possibility of bidirectional (feedback) effects to be explored. Future studies can collect longitudinal data to assess such bidirectional (feedback) effects. Longitudinal data may also be sought in future studies in order to explore the causal link between social control, learning process and production innovation. The model proposed and tested in this study is based on the notion that learning process partial mediates the influence of social control on production innovation. However, as a relationship develops, the model may also affect the evolution of a mix of control 
mechanisms used to achieve desired production innovation. Hence, an interesting approach for future research would be a longitudinal analysis of how control mechanisms used in production innovation. Third, we discuss only social control; we believe researchers should include control mechanism other than just social control when studying the production innovation of international joint ventures in China.

\section{Acknowledgement}

This research was supported by National Natural Science Found of China (Key Program) under Grant 70832003, National Natural Science Fund of China (NSFC) under Grant 70572095 and 70972108, Program for New Century Excellent Talents in University under Grant NCET07-0308.

\section{REFERENCES}

[1] K. M. Eisenhardt, "Control: Organizational and economics approaches," Management Science, Vol. 31, No. 2, pp. 134-149, 1985.

[2] W. G. Ouchi, "Markets, bureaucracies, and clans, administrative science quarterly,”Vol. 25, pp. 129-141, 1980.

[3] W. G. Ouchi and M. A. Maguire, "Organizational control: Two functions," Administrative Science Quarterly, Vol. 20, pp. 559-569, 1975.

[4] G. Hame, "Competition for competence and interpartner learning within international strategic alliances," Strategic Management Journal, Vol. 12, pp. 83-103, 1991.

[5] B. Kogut, "Joint ventures: Theoretical and empirical perspectives," Strategic Management Journal, Vol. 9, No. 4, pp. 319-322, 1988.

[6] J. F. Hennart, "A transaction costs theory of equity joint ventures: An empirical study of Japanese subsidiaries in the United States," Management Science, Vol. 37, No. 4, pp. 483-497, 1991.

[7] A. C. Inkpen and P. W. Beamish, "Knowledge, bargaining power and international joint venture instability," Academy of Management Review, Vol. 22, No. 1, pp. 177-202, 1997.

[8] M. Kotabe and K. S. Swan, "The role of strategic alliances in high-technology new product development," Strategic Management Journal, Vol. 16, No. 8, pp. 621636, 1995.

[9] J. Wind and V. Mahajan, "Issues and opportunities in new product development: An introduction to the special issue," Journal of Marketing Research, Vol. 34, pp. 1-12, 1997.
[10] A. M. Jaeger, "The transfer of organizational culture overseas: An approach to control in the multinational corporation," Journal of International Business Studies, Vol. 04, pp. 91-114, 1983.

[11] B. R. Baliga and A. M. Jaeger, "Multinational corporations: Control systems and delegation issues," Journal of International Business Studies, Vol. 04, pp. 25-40, 1984.

[12] R. D. Hisrich and P. Szirmai, "Developing a market-oriented economy: A Hungarian perspective," Entrepreneurship and Regional Development, Vol. 5, pp. 61-71, 1993.

[13] M. A. Lyles and I. S. Baird, "Performance of international joint ventures in two Eastern European countries: The case of Hungary and Poland," Management International Review, Vol. 34, No. 4, pp. 313-330, 1994.

[14] C. Schoonhoven, K. Eisenhardt, and K. Lyman, "Speeding products to market: Waiting time to first product introduction in new firms," Administrative Science Quarterly, Vol. 35, pp. 177-207, 1990.

[15] F. Damanpour, "Organizational innovation: A metaanalysis of effects of determinants and moderators," Academy of Management Journal, Vol. 34, No. 3, pp. 555-590, 1991.

[16] S. Gopalakrishnan and F. Damanpour, "A review of innovation research in economics, sociology and technology management," The International Journal of Management Science, Vol. 25, No. 1, pp. 15-28, 1997.

[17] J. C. Nunnally, "Psychometric theory," New York: McGraw-Hill, 1978.

[18] J. L. Price and C. W. Mueller, "Handbook of organizational measurement," Marshfield, MA: Pitman Publishing Inc. 1986.

[19] J. F. Hair, R. E. Anderson, R. L. Tatham, and B. J. Grablowsky, "Multivariate data analysis," Tulsa, OK: PPC Books, 1979.

[20] L. J. Cronbach, "Coefficient alpha and the internal structure of tests," Psychometrika, Vol. 16, No. 3, pp. 297334, 1951.

[21] A. M. Jaeger and B. R. Baliga, "Control systems and strategic adaption: Lessons from the Japanese experience," Strategic Management Journal, Vol. 6, pp. 115134, 1985.

[22] S. W. Chou, "Computer systems to facilitating organizational learning: IT and organizational context," Expert Systems with Applications, Vol. 24, pp. 273-280, 2003.

[23] H. M. Xie, C. Wang, X. C. Li, and Y. Y. Ou, "An empirical research of influencing technical innovation's factor," Studies in science of science, Vol. 25, No. 5, pp. 963-970, 2007. 


\section{Appendix}

Table 3. Social control (five indicator variables; Cronbach's $\alpha=0.803$

\begin{tabular}{lc}
\multicolumn{1}{c}{ Factor } & loadings \\
\hline $\begin{array}{l}\text { 1. We often have social meetings where our firm manag- } \\
\text { ers and foreign agents interact with each other }\end{array}$ & 0.745 \\
$\begin{array}{l}\text { 2. We frequently send our managers to this foreign } \\
\text { country to update our agents about product changes }\end{array}$ & 0.763 \\
$\begin{array}{l}\text { 3. Our firm managers make frequent trips to this for- } \\
\text { eign country to meet with our agents }\end{array}$ & 0.810 \\
$\begin{array}{l}\text { 4. Our foreign agents make frequent trips and visit our } \\
\text { business headquarters }\end{array}$ & 0.605 \\
$\begin{array}{l}\text { 5. We provide training to our foreign agents in our } \\
\text { business headquarters }\end{array}$ & 0.834 \\
\hline
\end{tabular}

Table 4. Learning process (five indicator variables; Cronbach's $\alpha=\mathbf{0 . 8 5 2}$

\begin{tabular}{lc}
\hline \multicolumn{1}{c}{ Factor } & loadings \\
\hline \begin{tabular}{l} 
1. Employees are wiling to contribute their expertise \\
\multicolumn{2}{c}{. I can contribute my working experience easily }
\end{tabular} & 0.668 \\
$\begin{array}{l}\text { 3. A learning community may eliminate temporal and } \\
\text { spatial constraints }\end{array}$ & 0.675 \\
$\begin{array}{l}\text { 4. My problems will be solved by adopting col- } \\
\text { leagues' opinions }\end{array}$ & 0.725 \\
$\begin{array}{l}\text { 5. I can obtain the solution for a specific problem from } \\
\text { a learning community }\end{array}$ & 0.796 \\
$\begin{array}{l}\text { 6. To solve the problems that may have in work prac- } \\
\text { tice, I need more innovative ideas }\end{array}$ & 0.783 \\
$\begin{array}{l}\text { 7. Learning community will facilitate the creation of } \\
\text { innovative ideas }\end{array}$ & 0.752 \\
\hline
\end{tabular}

Table 5. Product innovation (five indicator variables; Cronbach's $\alpha=0.854$

\begin{tabular}{lc}
\hline \multicolumn{1}{c}{ Factor } & loadings \\
\hline $\begin{array}{l}\text { 1. This organization's new products acquire many } \\
\text { innovation prizes }\end{array}$ & 0.768 \\
$\begin{array}{l}\text { 2. This organization develops abundance products } \\
\text { 3. This organization has more patent than others }\end{array}$ & 0.804 \\
$\begin{array}{l}\text { 4. This organization mostly profit result from new } \\
\text { products and service }\end{array}$ & 0.831 \\
$\begin{array}{l}\text { 5. This organization seeks out and acquires new tech- } \\
\text { nologies of improving process }\end{array}$ & 0.781 \\
\hline
\end{tabular}

